\title{
Arahan Pengembangan Hutan Rakyat untuk Penanganan Lahan Kritis di Kabupaten Sukabumi, Provinsi Jawa Barat
}

\author{
Direction for Development of Community Forests for Handling \\ Critical Land in Sukabumi Regency, West Java Province
}

Dharma Agustinus Sirait ${ }^{1}$, Widiatmaka ${ }^{1}$, dan 0 mo Rusdiana ${ }^{1}$

Diterima: 8 April 2021

Disetujui: 7 Juli 2020

\begin{abstract}
Abstrak: Kemampuan tanaman hutan rakyat sebagai alternatif pemenuhan kebutuhan bahan baku menjadi daya tarik tersendiri bagi industri perkayuan. Sementara itu Kabupaten Sukabumi adalah wilayah dengan luas wilayah terbesar di Provinsi Jawa Barat, sehingga berpotensi untuk pengembangan tanaman hutan rakyat. Penelitian ini bertujuan untuk menganalisis ketersediaan lahan yang dapat dikembangkan untuk tanaman hutan rakyat, menganalisis kesesuaian lahan tanaman hutan rakyat, dan merumuskan arahan pengembangan tanaman hutan rakyat di Kabupaten Sukabumi. Penelitian dilaksanakan di Kabupaten Sukabumi yaitu dari bulan Februari sampai Agustus 2019. Data yang digunakan adalah data bobot tiap-tiap kriteria kesesuaian lahan tanaman hutan rakyat dari narasumber ahli, data Satuan Peta Tanah dari BBSDLP, peta penggunaan lahan tahun 2019, peta RTRW, peta kawasan hutan, dan status perizinan. Metode yang digunakan adalah analisis spasial untuk penentuan lahan tersedia, Analytical Hierarchy Process (AHP) untuk penentuan bobot kriteria, Multi Criteria Evaluation (MCE) untuk menganalisis kesesuaian lahan, dan analisis spasial untuk penentuan arahan prioritas pengembangan. Hasil penelitian menunjukkan ketersediaan lahan untuk pengembangan hutan rakyat di Kabupaten Sukabumi yaitu sebesar 57,786 hektar. Luas lahan tersedia di Kabupaten Sukabumi yang tergolong sesuai untuk tanaman hutan rakyat (S1, S2, S3) adalah sebesar 57\%. Pengembangan tanaman hutan rakyat diarahkan pada lahan prioritas 1 seluas sebesar $83 \%$.
\end{abstract}

Kata Kunci: AHP, Kesesuaian lahan, MCE

\begin{abstract}
Community forest plants can be an alternative fulfillment of raw material for the timber industry. While Sukabumi Regency is region with the largest area in West Java Province, so it the potential for development of community forest plants. This study wants to find the availability of land for development community forest plants, analyzing the suitability of community forest plantations, and formulating direction for development community forest plants in Sukabumi Regency. The study was conducted in Sukabumi Regency, which began in February-August 2019. The data used is the weight of each criteria for suitability of community forest plants from experts, data Land Map Units from BBSDLP, land use maps, RTRW maps, forest area maps, and land licensing. The method used is spatial analysis for determining available land, Analytical Hierarchy Process (AHP) for determining criteria weights, Multi Criteria Evaluation (MCE) for analyzing land suitability, and spatial analysis for determining development priority directions. The results showed that availability land for development of community forest plants in Sukabumi Regency was 57,786 hectares. The available land area in Sukabumi Regency which is classified as suitable (S1, S2, S3) i.e 57\%. The development of community forest plants is directed at priority 1 , which is an $83 \%$.
\end{abstract}

Keywords: AHP, Land suitability, $M C E$

1 Program Studi Ilmu Perencanaan Wilayah, Departemen Ilmu Tanah dan Sumberdaya Lahan, Institut Pertanian Bogor

Korespondensi: dharma310881@gmail.com 


\section{PENDAHULUAN}

Pertumbuhan penduduk setiap tahun terus mengalami peningkatan, rata-rata laju pertumbuhan penduduk di Provinsi Jawa Barat pada tahun 2010-2017 adalah sebesar 1,54\% dan di Kabupaten Sukabumi sebesar 0,6\% (BPS Provinsi Jawa Barat 2018). Pertumbuhan penduduk akan meningkatkan kebutuhan masyarakat terhadap sumber daya alam, termasuk sumberdaya hutan. Sementara jumlah sumber daya hutan semakin berkurang dari waktu ke waktu. Kemampuan hutan rakyat sebagai alternatif pemenuhan kebutuhan bahan baku menjadi daya tarik tersendiri bagi industri perkayuan. Kesenjangan supply dan demand bahan baku kayu yang berasal dari hutan alam semakin memantapkan arti penting keberadaan hutan rakyat. Berdasarkan data dari Ditjen PHPL tahun 2016 tentang realisasi pemenuhan bahan baku industri nasional skala besar, peningkatan pasokan kayu hutan rakyat terjadi dari tahun 2008-2016 sebesar 4,33\%. Di sisi lain, penurunan pasokan kayu hutan alam terjadi dari tahun 2008-2016 sebesar $2,80 \%$.

Kabupaten Sukabumi merupakan wilayah yang paling luas di Provinsi Jawa Barat yaitu 4.145,70 km2 (BPS Provinsi Jawa Barat 2018), sehingga mempunyai potensi untuk pengembangan hutan rakyat. Hutan rakyat di Kabupaten Sukabumi memiliki dua fungsi, yaitu fungsi ekonomi dan fungsi ekologi (lingkungan). Secara ekonomi pengembangan hutan rakyat antara lain berfungsi sebagai penyedia bahan baku kayu yang akan mendorong berkembangnya berbagai kegiatan ekonomi yang berbasis kayu seperti penggergajian kayu, industri kerajinan dan lain-lain. Secara ekologis pengembangan hutan rakyat akan bermanfaat bagi perbaikan kualitas lahan, memperbaiki tata air, bahkan yang lebih besar, hutan rakyat akan menjaga keseimbangan ekosistem lingkungan. Oleh karena itu, berbagai penelitian dilakukan untuk analisis kesesuaian lahan dan perencanaan dan pengelolaan penggunaan lahan (Nyeko, 2012).

Dari sisi kebijakan pemerintah baik pemerintah pusat maupun pemerintah daerah, kegiatan pengembangan hutan rakyat merupakan salah satu kegiatan prioritas di sektor kehutanan. Di tingkat pusat dikembangkan kegiatan persemaian permanen untuk memberikan bibit tanaman hutan secara gratis kepada masyarakat, aneka usaha produktif dan di pemerintah daerah provinsi dengan kegiatan Unit Managemen Hutan Rakyat (UMHR), pembuatan persemaian, kawasan ekosistem esensial dan lainnya. Berdasarkan hal tersebut maka dilakukan penelitian di Kabupaten Sukabumi dengan tujuan untuk mengetahui: (a) ketersediaan lahan yang dapat dikembangkan untuk tanaman hutan rakyat, (b) menganalisis kesesuaian lahan untuk tanaman hutan rakyat, dan (c) merumuskan arahan pengembangan tanaman hutan rakyat di Kabupaten Sukabumi.

\section{METODE}

\section{Lokasi dan Waktu Penelitian}

Penelitian ini dilaksanakan di Kabupaten Sukabumi yang secara administratif berada di Provinsi Jawa Barat. Kabupaten Sukabumi terdiri dari 47 Kecamatan. Penelitian dilaksanakan selama 6 bulan yaitu dari Februari sampai Agustus 2019. Lokasi penelitian disajikan pada Gambar 1. 


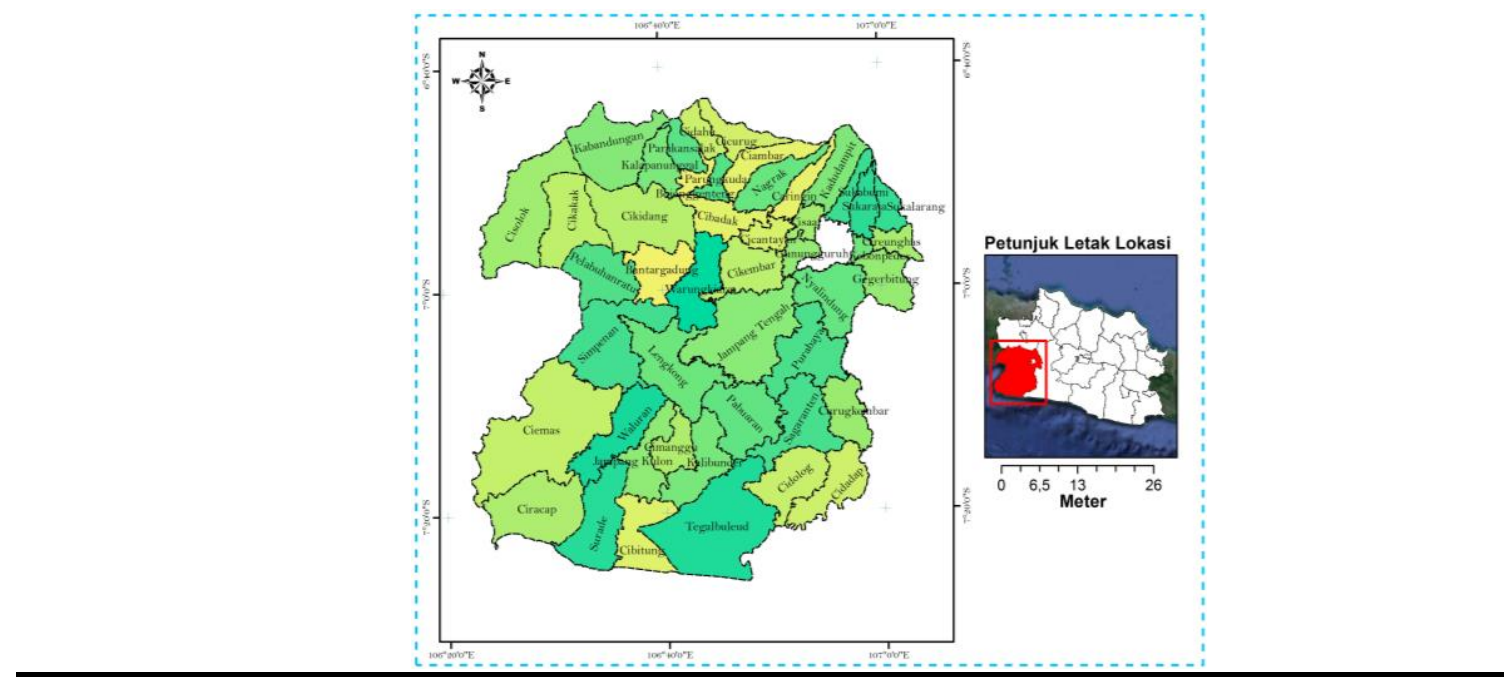

Gambar 1. Peta Lokasi Penelitian

\section{Jenis, Sumber , dan Teknik Pengumpulan Data}

Data yang digunakan dalam penelitian ini berupa data primer dan data sekunder. Data primer diperoleh melalui wawancara kepada narasumber ahli atau orang yang berpengalaman terkait dengan pengembangan tanaman hutan rakyat. Pengumpulan data primer dilakukan melalui wawancara dengan narasumber ahli yang menguasai tentang topik penelitian yang dikaji. Narasumber ahli tersebut terdiri dari 6 orang ahli meliputi 3 orang akademisi, 1 orang dari LITBANGHUT Kementerian Kehutanan, 1 orang dari Dinas Kehutanan Provinsi Jawa Barat, dan 1 orang dari Balai Lingkungan Hidup Kabupaten Sukabumi. Data sekunder meliputi data Satuan Peta Tanah skala 1:50.000 dari Balai Besar Litbang Sumberdaya Lahan Pertanian (BBSDLP), peta penggunaan lahan tahun 2019, peta pola ruang RTRW Kabupaten Sukabumi, peta status kawasan hutan dari Kementerian Kehutanan, Peta status perizinan lahan dari Badan Pertanahan Nasional, dan data-data lain yang relevan dengan penelitian yang dikaji yang diperoleh dari penelusuran data dan literatur dari instansi-instansi terkait.

\section{METODE}

\section{Analisis Ketersediaan Lahan}

Analisis ketersediaan lahan dilakukan pada tahap awal untuk pemilihan wilayah yang akan dijadikan sebagai wilayah pengembangan, sehingga dapat dilokalisir dan dititikberatkan hanya pada lokasi-lokasi yang telah dideliniasi sebagai wilayah pengembangan (Widiatmaka, 2013). Ketersediaan lahan untuk pengembangan tanaman hutan rakyat dilakukan dengan mempertimbangkan kriteria: (1) Peta penggunaan lahan eksisting tahun 2019 dengan kategori penggunaan lahan tidak produktif/belum termanfaatkan, (2) Peta pola ruang yang merupakan kawasan pertanian lahan kering, (3) Peta status kawasan hutan yang merupakan Areal Penggunaan Lain, dan (4) Status perizinan yaitu pada wilayah belum memiliki izin pengelolaan baik HGU perkebunan maupun untuk aktivitas pertambangan. Kriteria penentuan lahan tersedia disajikan pada Tabel 1. 
Tabel 1. Kriteria Penentuan Lahan Tersedia

\begin{tabular}{llll}
\hline Tutupan Lahan & Pola Ruang & Kawasan Hutan & Status Perizinan \\
\hline \multirow{2}{*}{ Semak belukar } & Kaw. & & Tidak Termasuk \\
& $\begin{array}{l}\text { Peruntukan } \\
\text { Pertanian }\end{array}$ & Area Penggunaan & \\
Lahan terbuka & Lahan Kering & Lain & \\
\hline
\end{tabular}

\section{Analisis Kesesuaian Lahan}

Prasyarat perencanaan penggunaan lahan adalah penilaian kesesuaian lahan (Akinci, et al. 2013), dan melibatkan keputusan untuk menggunakan sumber daya yang tersedia (Mokarram dan Aminzadeh, 2010). Analisis kesesuaian lahan dilakukan pada hasil analisis lahan tersedia untuk pengembangan tanaman hutan rakyat dan satuan peta tanah skala 1:50.000 dari Balai Besar Litbang Sumberdaya Lahan Pertanian (BBSDLP). Metode yang digunakan yaitu Multi Criteria Evaluation (MCE). MCE merupakan perangkat pengambilan keputusan yang dikembangkan untuk masalah-masalah kompleks multikriteria yang mencakup aspek kualitatif dan atau kuantitatif dalam proses pengambilan keputusan (Suriani et al, 2019). Umar et al (2017) menggunakan metode MCE untuk mengevaluasi kesesuaian lahan untuk kawasan pemukiman di Kota padang, adapun Qommarudin (2014) menggunakan metode MCE untuk mengetahui indikasi lokasi lahan kritis berdasarkan kriteria dan indikator penentu lahan kritis.

Kriteria yang digunakan meliputi jenis tanah, kelerengan, curah hujan, kedalaman tanah, elevasi, drainase, tekstur, jarak ke sumber air, $\mathrm{pH}$, dan KTK. Penentuan bobot untuk tiap-tiap kriteria kesesuaian tanaman hutan rakyat ditentukan berdasarkan pendapat pakar dengan menggunakan metode Analytical Hierarchy Process (AHP). Metode AHP merupakan salah satu sistem penunjang keputusan yang dapat menguraikan masalah multi faktor/multi aspek ataupun multi kriteria yang kompleks menjadi suatu hirarki/level (Saaty, 1986). Yang et al (2011) dan Umar (2016) menggunakan metode AHP dalam penentuan nilai bobot dan harkat untuk kriteria.

Metode AHP melibatkan pakar dalam penentuan bobot. Penggunaan metode MCE dalam penentuan bobot kesesuaian lahan didasarkan tingkat kesesuian parameter tersebut terhadap tanaman hutan rakyat. Skor yang diberikan berdasarkan kontribusi setiap sub-kriteria yang diberi rentang nilai 1 sampai 5 mengacu pada Widiatmaka et al. (2016). Nilai tertinggi diberikan pada sub-kriteria yang sangat berpengaruh pada lahan hutan rakyat, sementara skor terendah diberikan pada subkriteria yang kurang berpengaruh pada lahan pertanian (Tabel 2). Kelas kesesuaian lahan menggunakan 4 tingkatan kelas kesesuaian meliputi kelas sangat sesuai (S1), kelas cukup sesuai (S2), kelas sesuai marginal (S3), dan kelas tidak sesuai (N).

Tabel 2. Kriteria, Sub-Kriteria Serta Bobot Skor yang Diberikan dalam Metode MCE

\begin{tabular}{|c|c|c|c|c|c|c|c|}
\hline Kriteria & Sub-Kriteria & Bobot & Skor & Kriteria & Sub-kriteria & Bobot & Skor \\
\hline \multirow{5}{*}{ Jenis tanah } & Inseptisol & & 4 & \multirow{5}{*}{ PH } & Netral & \multirow{5}{*}{$\begin{array}{l}\text { Hasil } \\
\text { AHP }\end{array}$} & 4 \\
\hline & Entisol & & 3 & & Agak masam & & 3 \\
\hline & Alfisol & Hasil & 3 & & Agak Basa & & 3 \\
\hline & Ultisol & & 2 & & Masam & & 2 \\
\hline & Andosol & & 1 & & Basa & & 1 \\
\hline \multirow{4}{*}{$\begin{array}{l}\text { Kedalaman } \\
\text { tanah }\end{array}$} & Sangat Dalam & & 4 & \multirow{4}{*}{ KTK } & Tinggi & & 4 \\
\hline & Dalam & Hasil & 3 & & Sedang & Hasil & 3 \\
\hline & Dangkal & AHP & 2 & & Rendah & AHP & 2 \\
\hline & Sangat Dangkal & & 1 & & Sangat rendah & & 1 \\
\hline \multirow{4}{*}{ Drainase } & Baik & & 4 & \multirow{4}{*}{$\begin{array}{l}\text { Curah } \\
\text { Hujan }\end{array}$} & $0-3000$ & & 4 \\
\hline & Agak Baik & Hasil & 3 & & $>3000-3500$ & Hasil & 3 \\
\hline & Agak Buruk & AHP & 2 & & $>3500-4000$ & AHP & 2 \\
\hline & Buruk & & 1 & & $>4000-4500$ & & 1 \\
\hline
\end{tabular}




\begin{tabular}{|c|c|c|c|c|c|c|c|}
\hline Kriteria & Sub-Kriteria & Bobot & Skor & Kriteria & Sub-kriteria & Bobot & Skor \\
\hline \multirow{6}{*}{ Tekstur } & & & & & $>4.500$ & \multirow{6}{*}{$\begin{array}{l}\text { Hasil } \\
\text { AHP }\end{array}$} & 1 \\
\hline & Halus & \multirow{5}{*}{$\begin{array}{l}\text { Hasil } \\
\text { AHP }\end{array}$} & 4 & & $0-500 \mathrm{~m}$ & & 4 \\
\hline & Agak Halus & & 3 & & $>500-1000 \mathrm{~m}$ & & 3 \\
\hline & Sedang & & 2 & Elevasi & $>1000-1500 \mathrm{~m}$ & & 2 \\
\hline & Agak Kasar & & 1 & & $>1500-2000 \mathrm{~m}$ & & 1 \\
\hline & Kasar & & 1 & & $>2000 \mathrm{~m}$ & & 1 \\
\hline \multirow{6}{*}{ Lereng } & $0-3 \%$ & & 4 & \multirow{6}{*}{$\begin{array}{l}\text { Jarak ke } \\
\text { sumber } \\
\text { air }\end{array}$} & $0-1000 \mathrm{~m}$ & \multirow{6}{*}{$\begin{array}{l}\text { Hasil } \\
\text { AHP }\end{array}$} & 4 \\
\hline & $>3-8 \%$ & & 4 & & $1000-2000 \mathrm{~m}$ & & 3 \\
\hline & $>8-0.105 \%$ & Hasil & 3 & & $2000-3000 \mathrm{~m}$ & & 2 \\
\hline & $>0.105-0.205 \%$ & AHP & 2 & & $>3000 \mathrm{~m}$ & & 1 \\
\hline & $>0.205-40 \%$ & & 1 & & & & \\
\hline & $>40-60 \%$ & & 1 & & & & \\
\hline
\end{tabular}

\section{Merumuskan Arahan Prioritas Pengembangan Tanaman Hutan Rakyat}

Elemen tanah terlalu banyak digunakan dan dieksploitasi, sehingga menghadapi masalah yang berbeda seperti erosi tanah, penebangan air, penipisan air tanah, limpasan berat, kehilangan produktivitas, dll (Zolekar dan Bhagat, 2015). Tanah yang terdegradasi mengancam sekuritas makanan dan energi, ketersediaan dan kualitas air, keanekaragaman hayati, kehidupan manusia, dll. (Bhagat, 2012). Rumusan arahan prioritas pengembangan dilakukan untuk mengarahkan pengembangan hutan rakyat pada lahan-lahan suboptimal atau yang telah mengalami degradasi menyebabkan lahan tersebut menjadi kritis. Lahan kritis merupakan lahan atau tanah yang saat ini tidak produktif karena pengelolaan dan penggunaan tanah yang kurang memperhatikan syaratsyarat konservasi tanah dan air. Penggunaan kriteria lahan kritis dimaksudkan untuk dapat meningkatkan kualitas dari lahan tersebut. Data yang digunakan yaitu data spasial lahan kritis di Kabupaten Sukabumi dengan hasil analisis kesesuaian lahan dengan hanya menggunakan lahan yang sesuai (S1, S2, S3). Selengkapnya disajikan pada Tabel 3.

Tabel 3. Penentuan Arahan Prioritas Pengembangan

\begin{tabular}{ll}
\hline \multicolumn{1}{c}{ Prioritas Pengembangan 1 } & Prioritas Pengembangan 2 \\
\hline Kelas kesesuaian lahan & \\
S1 (Sangat sesuai) & \\
S2 (Cukup sesuai) & Di luar prioritas \\
S3 (Sesuai marjinal) & Pengembangan 1 \\
Kategori lahan kritis & \\
Sangat kritis & \\
Kritis & \\
\hline
\end{tabular}

Prioritas pengembangan dikategorikan ke dalam 2 prioritas pengembangan meliputi prioritas pengembangan 1 dan prioritas pengembangan 2. Penentuan prioritas pengembangan dengan asumsi bahwa semakin tinggi tingkat kekritisan lahan tersebut semakin diarahkan untuk pengembangan tanaman hutan rakyat. Prioritas pengembangan 1 merupakan lahan tersedia yang termasuk ke dalam kelas kesesuaian lahan S1, S2, S3 dengan kategori lahan kritis meliputi sangat kritis dan kritis. Adapun prioritas pengembangan 2 yaitu lahan tersedia yang diluar prioritas 1 .

\section{HASIL DAN PEMBAHASAN}

\section{Ketersediaan Lahan}

Ketersediaan lahan untuk pengembangan tanaman hutan rakyat di Kabupaten Sukabumi yaitu sebesar 57,786 ha. Lahan tersedia tersebut merupakan kombinasi dari kriteria penggunaan lahan berupa penggunaan lahan semak belukar, kriteria pola ruang yaitu yang termasuk ke dalam kawasan peruntukan pertanian lahan kering, kriteria 
kawasan hutan yaitu yang termasuk ke dalam area penggunaan lain, dan kriteria status perizinan yaitu yang belum memiliki isin usaha. Luas lahan tersedia di Kabupaten Sukabumi disajikan pada Tabel 4. Persebaran spasial disajikan pada Gambar 2.

Tabel 4. Luas Lahan Tersedia di Kabupaten Sukabumi

\begin{tabular}{|c|c|c|c|c|}
\hline $\begin{array}{l}\text { Tutupan } \\
\text { Lahan }\end{array}$ & Pola Ruang & Kawasan Hutan & $\begin{array}{c}\text { Status } \\
\text { Perizinan }\end{array}$ & luas (ha) \\
\hline $\begin{array}{l}\text { Semak } \\
\text { belukar }\end{array}$ & $\begin{array}{l}\text { Kaw. Peruntukan Pertanian } \\
\text { Lahan Kering }\end{array}$ & $\begin{array}{l}\text { Area Penggunaan } \\
\text { Lain }\end{array}$ & $\begin{array}{l}\text { Belum } \\
\text { memiliki izin }\end{array}$ & 57,277 \\
\hline $\begin{array}{l}\text { Lahan } \\
\text { terbuka }\end{array}$ & $\begin{array}{l}\text { Kaw. Peruntukan Pertanian } \\
\text { Lahan Kering }\end{array}$ & $\begin{array}{l}\text { Area Penggunaan } \\
\text { Lain }\end{array}$ & $\begin{array}{l}\text { Belum } \\
\text { memiliki izin }\end{array}$ & 509 \\
\hline Jumlah & & & & 57,786 \\
\hline
\end{tabular}

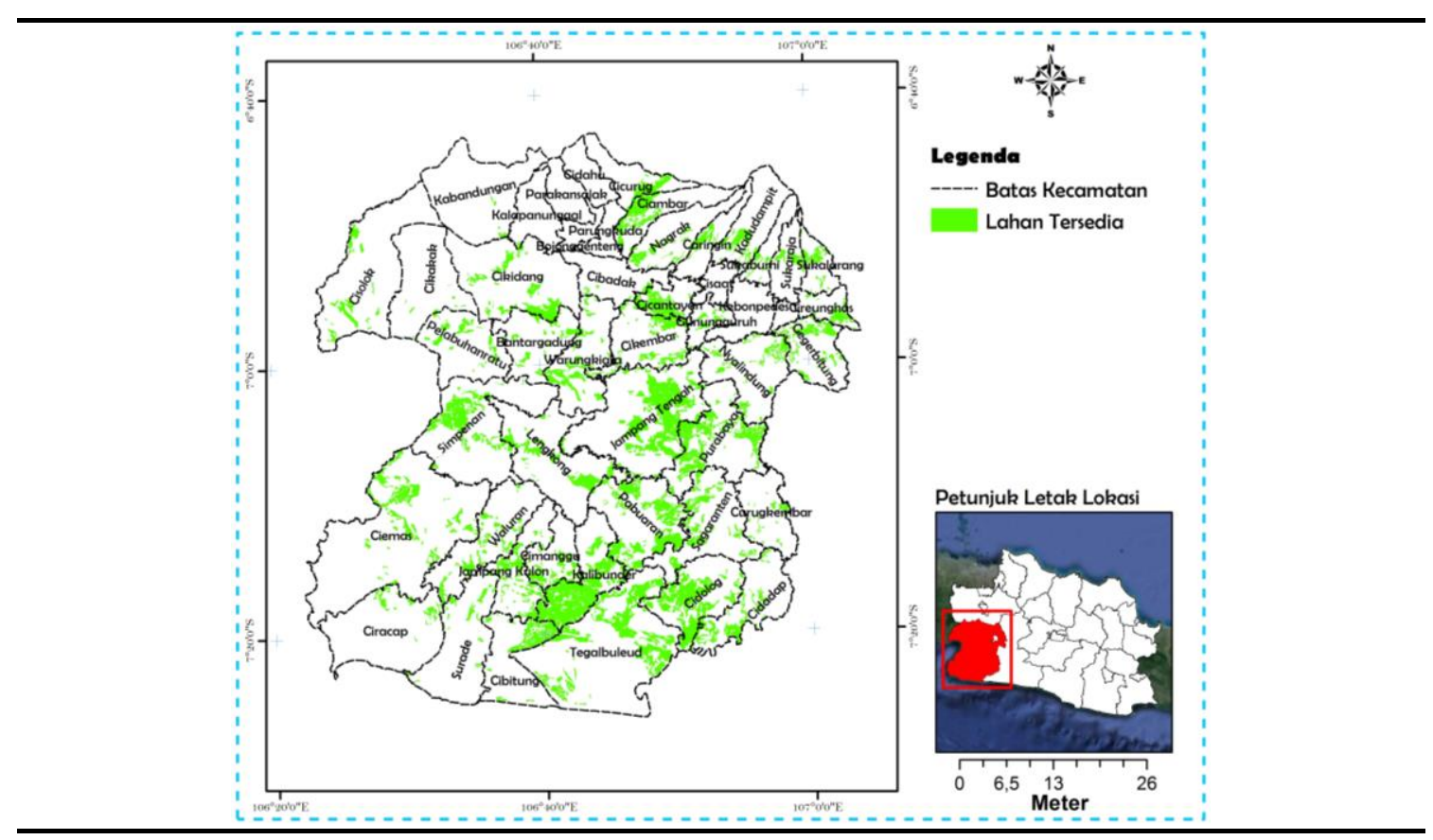

Gambar 2. Persebaran Spasial Lahan Tersedia di Kabupaten Sukabumi

Secara spasial lahan tersedia di Kabupaten Sukabumi relatif menyebar ke seluruh wilayah dengan utamanya terkonsentrasi di bagian timur dan selatan Kabupaten Sukabumi. Jika ditinjau berdasarkan wilayah kecamatan maka wilayah kecamatan yang memiliki luas lahan tersedia terbesar yaitu Kecamatan Jampang Tengah dengan luas 5,212 ha (9\%), Tegalbuleud dengan luas 4,643 (8\%), dan Kalibunder dengan luas 4,571 (7,9\%) dari luas keseluruhan lahan tersedia di Kabupaten Sukabumi.

\section{Kesesuaian Lahan Tanaman Hutan Rakyat}

Hasil penilaian pakar dalam penentuan bobot terhadap kesesuaian lahan untuk tanaman hutan rakyat disajikan pada Gambar 3. Nilai bobot tertinggi berdasarkan penilaian pakar adalah curah hujan $(0,202)$, sedangkan yang terendah yaitu KTK $(0,054)$. Konsistensi penilaian pakar dalam penentuan bobot sebesar 0,03 . Marimin dan Maghfiroh (2010) menyatakan bahwa nilai inconsistency ratio yang dapat diterima adalah kurang dari 1 , dalam penelitian ini penilaian pakar memiliki in consistency sebesar 0,03 , yang berarti penilaian pakar cukup konsisten. 


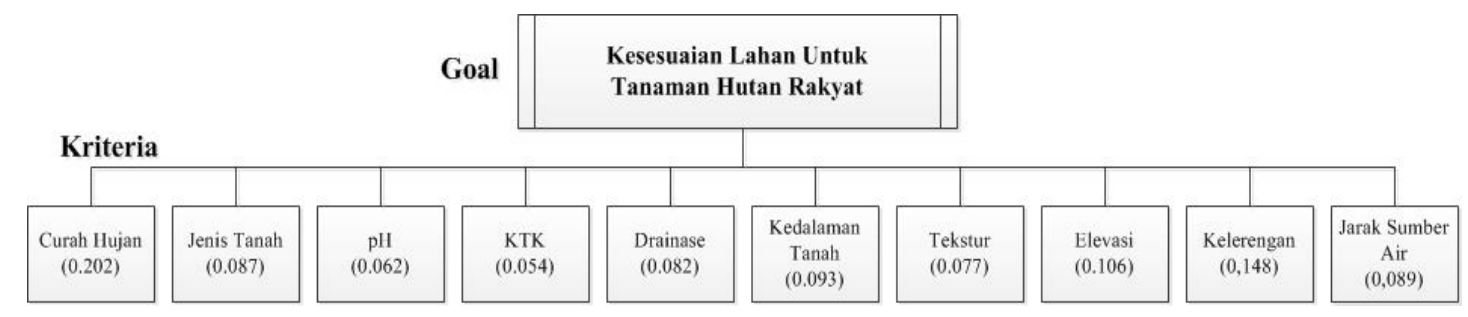

\section{Gambar 3. Hasil Penilaian Pakar dalam Metode AHP}

Hasil analisis kesesuaian lahan di Kabupaten Sukabumi untuk tanaman hutan rakyat didominasi oleh kelas tsesuai marjinal (S3) dengan interval nilai indeks $(>0,245$ 0,283 ) yaitu seluas 26,088 ha atau $45 \%$ dari luas lahan tersedia yang dianalisis. Sementara kelas kesesuaian lahan cukup sesuai (S2) menempati urutan kedua dengan nilai indeks $(>0,283-0,320)$ seluas 24,233 ha $(42 \%)$, adapun kelas kesesuaian sangat sesuai (S1) dengan nilai indeks $(>0,320-0,358)$ dengan luas 5,770 ha (10\%). Sementara itu kelas tidak sesuai $(\mathrm{N})$ untuk tanaman hutan rakyat memiliki luasan yang relati kecil yaitu sebesar 1,694 ha (3\%) dari keseluruhan luas lahan tersedia yang dianalisis. Hasil analisis kesesuaian lahan disajikan pada Tabel 5. Peta kesesuaian lahan tanaman hutan rakyat di Kabupaten Sukabumi disajikan pada Gambar 4.

Tabel 5. Kesesuaian Lahan Tanaman Hutan Rakyat

\begin{tabular}{llrr}
\hline \multirow{2}{*}{ Kelas Kesesuaian } & \multirow{2}{*}{ Indeks Kesesuaian Lahan } & \multicolumn{2}{c}{ Luas } \\
\cline { 3 - 4 } & & \multicolumn{1}{c}{ ha } & \multicolumn{1}{c}{$\%$} \\
\hline S1 (Sangat Sesuai) & $>0,320-0,358$ & 2470 & 10 \\
S2 (Cukup Sesuai) & $>0,283-0,320$ & 233 & 42 \\
S3 (Sesuai Marjinal) & $>0,245-0,283$ & 26,088 & 45 \\
N (Tidak Sesuai) & $<=0,245$ & 1,694 & 3 \\
\hline Jumlah & & $\mathbf{5 7 , 7 8 4}$ & $\mathbf{1 0 0}$ \\
\hline
\end{tabular}

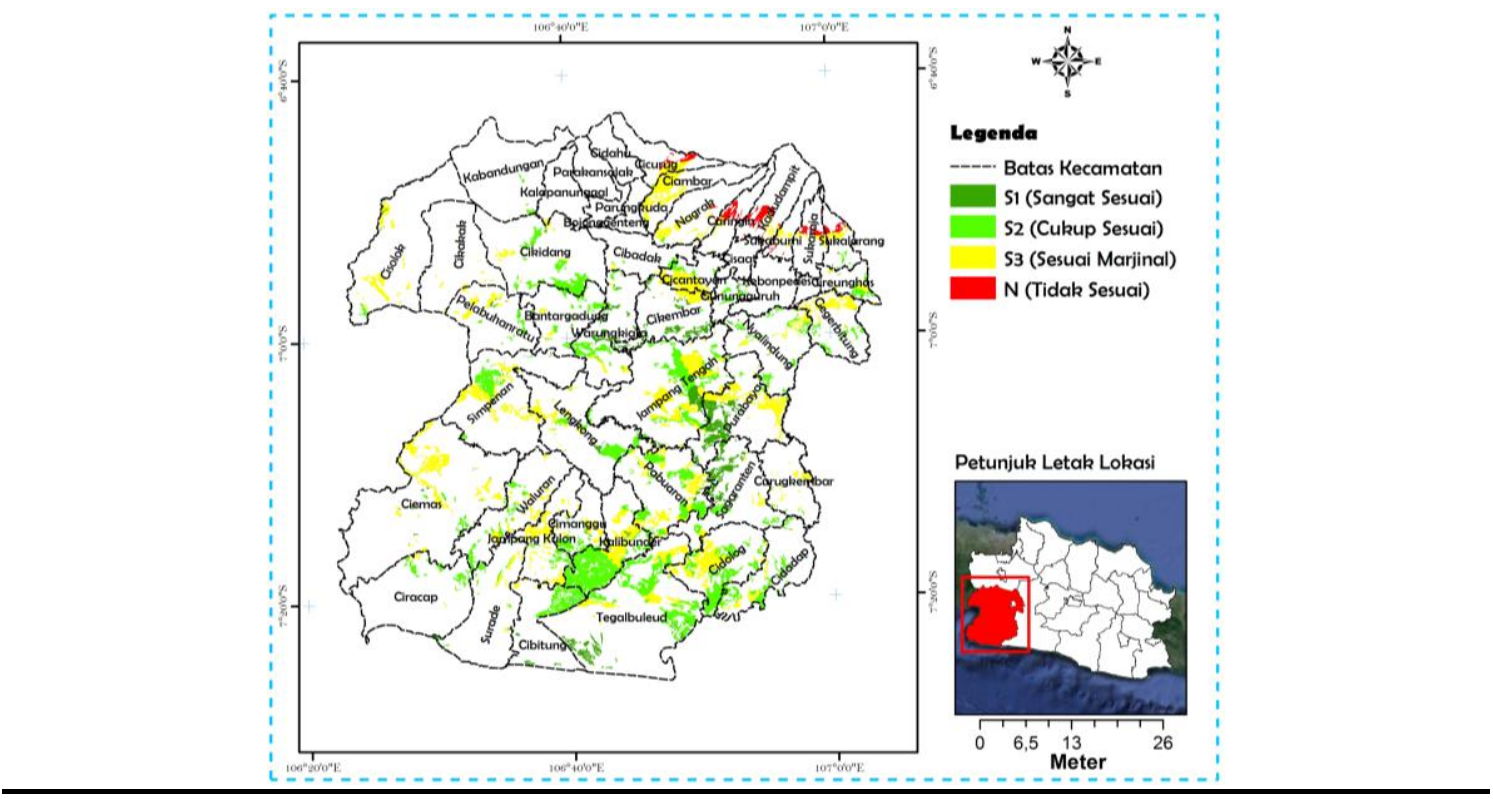

Gambar 4. Peta Kesesuaian Lahan 
Luas lahan yang termasuk ke dalam kelas tidak sesuai utamanya dipengaruhi oleh beberapa kriteria yang memiliki skor rendah meliputi kelerengan, $\mathrm{pH}$, dan jarak dari sumber air. Secara umum wilayah Kabupaten Sukabumi memang didominasi kelas lereng curam sampai dengan terjal, adapun kandungan $\mathrm{pH}$ didominasi $\mathrm{pH}$ masam dan agak masam sementara untuk jarak dari sumber air lahan-lahan tersebutrelatif jauh dari sumber air (sungai utama) yaitu pada jarak $>3000 \mathrm{~m}$.

Kategori kelas kesesuaian lahan di Kabupaten Sukabumi disajikan pada tiap-tiap kecamatan dengan hanya mengambil kelas kesesuaian lahan sesuai (S1, S2, S3) seperti pada Tabel 6. Lahan tersedia yang sesuai untuk pengembangan hutan rakyat rata-rata menyebar ke berbagai kecamatan, artinya tidak terkonsentrasi pada satu atau beberapa wilayah kecamatan saja, menandakan bahwa pengembangan hutan rakyat tersebut dapat memberikan nilai ekonomi secara menyeluruh di Kabupaten Sukabumi.

Tabel 7. Prioritas Pengembangan Tanaman Hutan Rakyat

\begin{tabular}{|c|c|c|}
\hline Kesesuaian Lahan & Kecamatan & Luas (ha) \\
\hline $\mathrm{N}$ & $\begin{array}{l}\text { Caringin, Cicurug, Cisaat, Gegerbitung, Kadudampit, Kebonpedes, } \\
\text { Nagrak, Sukabumi, Sukalarang, Sukaraja }\end{array}$ & 1,694 \\
\hline S1 & $\begin{array}{l}\text { Bantargadung, Ciambar, Cibitung, Cicantayan, Cidadap, Ciemas, } \\
\text { Cikembar, Cikidang, Cimanggu, Cireunghas, Cisolok, Curugkembar, } \\
\text { Gegerbitung, Gunungguruh, Jampang Tengah, Kabandungan, } \\
\text { Kalapanunggal, Kalibunder, Kebonpedes, Lengkong, Nagrak, Nyalindung, } \\
\text { Pabuaran, Pelabuhanratu, Purabaya, Sagaranten, Simpenan, Surade, }\end{array}$ & 5,770 \\
\hline S2 & $\begin{array}{l}\text { Bantargadung, Cibadak, Cibitung, Cicantayan, Cicurug, Cidadap, Cidolog, } \\
\text { Ciemas, Cikembar, Cikidang, Cimanggu Ciracap, Cireunghas, Cisaat, } \\
\text { Cisolok, Curugkembar, Gegerbitung, Gunungguruh, Jampang Kulon, } \\
\text { Jampang Tengah, Kabandungan, Kalibunder, Lengkong, Nagrak, } \\
\text { Nyalindung, Pabuaran, Pelabuhanratu, Purabaya, Sagaranten, Simpenan, } \\
\text { Sukalarang, }\end{array}$ & 24,233 \\
\hline S3 & $\begin{array}{l}\text { Bantargadung, Caringin, Ciambar, Cibadak, Cibitung, Cicantayan, } \\
\text { Cicurug, Cidadap, Cidolog, Ciemas, Cikakak, Cikembar, Cikidang, } \\
\text { Cimanggu, Ciracap, Cireunghas, Cisaat, Cisolok, Curugkembar, } \\
\text { Gegerbitung, Gunungguruh, Jampang Kulon, Jampang Tengah, } \\
\text { Kabandungan, Kadudampit, Kalapanunggal, Kalibunder, Lengkong, } \\
\text { Nagrak, Nyalindung, Pabuaran, Parungkuda, Pelabuhanratu, Purabaya, } \\
\text { Sagaranten, Simpenan, Sukabumi, Sukalarang, Sukaraja, Surade, } \\
\text { Tegalbuleud, Waluran, Warungkiara }\end{array}$ & 26,088 \\
\hline
\end{tabular}

\section{Arahan dan Prioritas Pengembangan Tanaman Hutan Rakyat}

Terdapat luas lahan sebesar 46,632 ha (83,2\%) dari luas lahan tersedia di Kabupaten Sukabumi yang dikategorikan ke dalam prioritas pengembangan 1, sedangkan prioritas pengembangan 2 seluas 9,447 ha atau 16,8\% (Tabel 7). Prioritas 1 merupakan lahan tersedia yang berada pada kategori sesuai (S1, S2, S3) dan terletak pada kriteria lahan kritis terletak pada kategori sangat kritis dan kritis. Lahan yang termasuk ke dalam prioritas 1 dapat menjadi alternatif lahan yang dapat dimanfaatkan untuk pengembangan hutan rakyat sehingga selain dapat mendorong peningkatan ekonomi juga dapat memperbaiki kualitas lahan tersebut. Peta arahan prioritas pengembangan disajikan pada Gambar 5.

Tabel 7. Prioritas Pengembangan Tanaman Hutan Rakyat

\begin{tabular}{lllcl}
\hline \multirow{2}{*}{ Prioritas } & \multirow{2}{*}{ Kelas Kesesuaian Lahan } & \multirow{2}{*}{ Kategori Lahan Kritis } & luas \\
& ha & \% \\
\hline \multirow{2}{*}{ Prioritas 1 1} & S1 & Kritis & 2,305 & 4,1 \\
& S2 & Sangat Kritis & 2,276 & 4,1 \\
& Kritis & 1,496 & 2,7 \\
\hline
\end{tabular}




\begin{tabular}{lllrr}
\hline \multirow{2}{*}{ Prioritas } & \multirow{2}{*}{ Kelas Kesesuaian Lahan } & Kategori Lahan Kritis & \multicolumn{1}{c}{ luas } & \multicolumn{1}{c}{$\%$} \\
\cline { 2 - 5 } & S2 & Sangat Kritis & 18,793 & 33,5 \\
& S3 & Kritis & 5,669 & 10,1 \\
Jumlah & S3 & Sangat Kritis & 16,094 & 28,7 \\
& S1 & & $\mathbf{4 6 , 6 3 2}$ & $\mathbf{8 3}$ \\
& S1 & Agak Kritis & 1,018 & 1,8 \\
& S1 & Potensial Kritis & 102 & 0,2 \\
& S2 & Tidak Kritis & 70 & 0,1 \\
Prioritas & S2 & Agak Kritis & 3,791 & 6,8 \\
& S2 & Potensial Kritis & 74 & 0,1 \\
& S3 & Tidak Kritis & 79 & 0,1 \\
& S3 & Agak Kritis & 4,125 & 7,4 \\
& S3 & Potensial Kritis & 131 & 0,2 \\
Jumlah & & Tidak Kritis & 57 & 0,1 \\
Jumlah Kes Keluruhan & & & \\
\hline
\end{tabular}

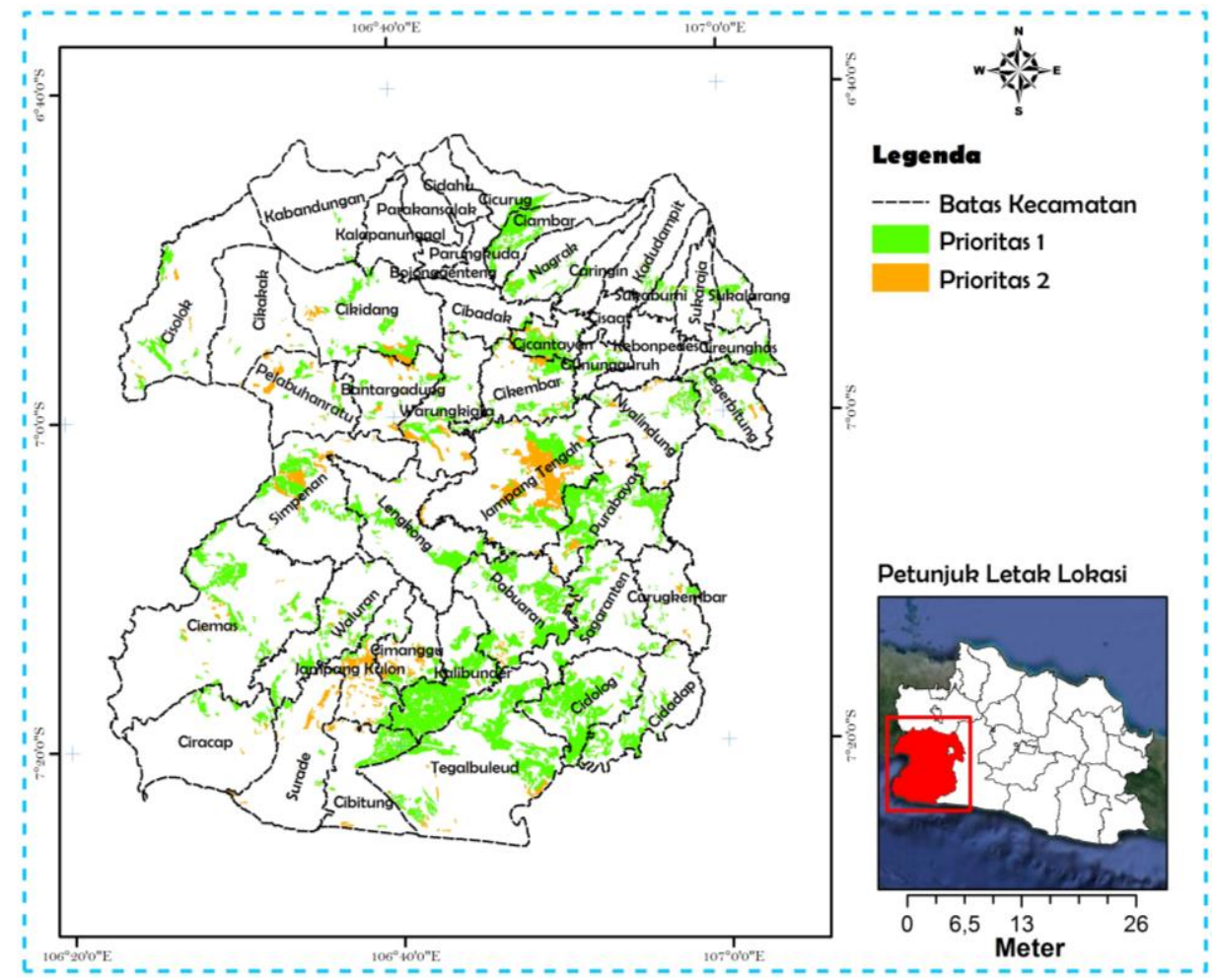

Gambar 5. Peta Arahan Pengembangan Tanaman Hutan Rakyat

\section{DISKUSI}

Kombinasi antara pendekatan penilaian pakar dan system pengambilan keputusan multi kriteria dalam penilaian kesesuaian lahan tanaman hutan rakyat memberikan hasil yang lebih akurat dibandingkan metode penilaian kesesuaian lahan konvensional. Banyaknya kriteria yang dipertimbangkan serta keterlibatan pakar dalam proses penilaian dapat membantu peneliti dalam pengambilan keputusan yang lebih rasional. 


\section{KESIMPULAN}

Ketersediaan lahan untuk pengembangan tanaman hutan rakyat di Kabupaten Sukabumi cukup luas yaitu sebesar 57,786 ha atau 13,88\%. Luas lahan tersedia di Kabupaten Sukabumi yang sesuai (S1, S2, S3) adalah sebesar 56,090 atau 97\% dari luas lahan tersedia. Terdapat luas lahan tersedia dan sesuai untuk tanaman hutan rakyat sebesar 46,632 ha (83\%) di Kabupaten Sukabumi yang diarahkan ke dalam prioritas 1 yaitu lahan yang dapat dimanfaatkan untuk pengembangan hutan rakyat sehingga selain dapat mendorong peningkatan ekonomi juga dapat menjadi alternatif penanganan dari lahan kritis.

\section{DAFTAR PUSTAKA}

Akinci, H., Ozalp, AY., Turgut, B. 2013. Agricultural land use suitability analysis using GIS and AHP technique. Computers and Electronics in Agriculture. 97 (2013):71-82

Badan Pusat Statistik Provinsi Jawa Barat Tahun 2018. 2018. Provinsi Jawa Barat Dalam Angka Tahun 2018. Jawa Barat (ID): BPS Provinsi Jawa Barat.

Bhagat, VS., 2012. Use of remote sensing techniques for robust digital change detection of land: a review. Recent Patents Space Technol. 2 (2) 123-144

Hardjowigeno, S., dan Widiatmaka. 2007. Evaluasi Kesesuaian Lahan dan Perencanaan Tataguna Lahan. Yogyakarta (ID): Gadjah Mada University Press.

Marimin, Maghfiroh, N.. 2010. Aplikasi Teknik Pengambil Keputusan dalam Manajemen Rantai Pasok. Bogor (ID): IPB Press.

Mokarram, M., Aminzadeh, F.. 2010. GIS-based multicriteria land suitability evaluation using ordered weight averaging with fuzzy quantifier: a case study in Shavur Plain, Iran. The International Archives of the Photogrammetry, Remote Sensing and Spatial Information Sciences. 38 (II):508-512

Nyeko, M. 2012. GIS and multi-criteria decision analysis for land use resourceplanning. J. Geogr. Inform. Syst. 4(4):341-348.

Qomaruddin, Agus, M. 2014. Sistem Informasi Geografis Pemetaan Bencana Alam Menggunakan Google Maps. Jurnal Teknik Informatika, 14(26):115-116.

Saaty, TL. 1993. Pengambilan Keputusan Bagi Para Pemimpin. Jakarta (ID): Terjemahan P.T. Pustaka Binaman Pressindo.

Suriani, Djafar, Mey, Saleh, F. 2019. Pemetaan Lahan Kritis dengan Metode Multi Criteria Evaluation di Sub DAS Amohalo. Jurnal Geografi Aplikasi Dan Teknologi. 3,(1): 2019.

Umar, I. 2016. Mitigasi Bencana Banjir pada Kawasan Permukiman Di Kota Padang Provinsi Sumatera Barat. [Disertasi]. Bogor: Institut Pertanian Bogor.

Umara, I., Widiatmaka, Pramudya, B., Barus, B. 2017. Evaluasi Kesesuaian Lahan Untuk Kawasan Permukiman Dengan Metode Multi Criteria Evaluation Di Kota Padang. Jurnal Pengelolaan Sumberdaya Alam dan Lingkungan. 7 (2):148-154

Widiatmaka. 2013. Analisis Sumberdaya Wilayah untuk Perencanaan Tataguna Lahan. Bogor (ID): Institut Pertanian Bogor

Widiatmaka, Ambarwulan, W., Sudarsono. 2016. Spatial Multi-Criteria Decision Making for Delineating Agricultural Land in Jakarta Metropolitan Area's Hinterland: Case Study of Bogor Regency, West Java. Agrivita Journal of Agricultural Science. 38(2): 105-115

Yang, M., Qian, X., Zhang, Y., Sheng, J., Shen, D., Ge, Y. 2011. Spatian Multicriteria Dicision Analysis of Flood Risks in Aging Dam Management in China. International Journal of Enviromental Research and Public Health 8(5):1368-1387.

Zolekar., RB, Bhagat, VS. 2015. Multi-criteria land suitability analysis for agriculture in hilly zone: Remote sensing and GIS approach. Computers and Electronics in Agriculture. 118 (2015):300-321 